\title{
PYELONEPHRITIS IN PREGNANCY: A RARE CASE
}

\author{
Preeti Amit Kale ${ }^{1}$
}

\section{HOW TO CITE THIS ARTICLE:}

Preeti Amit Kale. "Pyelonephritis in Pregnancy: A Rare Case". Journal of Evolution of Medical and Dental Sciences 2015; Vol. 4, Issue 51, June 25; Page: 8958-8960, DOI:10.14260/jemds/2015/1300

ABSTRACT: Urinary tract infection is a very much common during pregnancy. It has been observed it is taken very lightly and may get worsen in the form of pyelonephritis. Pyelonephritis is associated with complications in pregnancy if not treated completely. Here is a case report which was difficult to treat but was treated successfully with good neonatal outcome. She required surgical assistance to relive her symptoms and treat the disease. There are lot of observational comparative studies done for the pyelonephritis during pregnancy.

INTRODUCTION: Pyelonephritis is a common complication of pregnancy. It is also exacerbated by immunocompromised states and also the sickle cell gene.(1) Karen L. Archabald and et all have observed pyelonephritis goes on worsening as pregnancy advances if not treated correctly.(2) Pyelonephritis in pregnancy is associated with multiple complications, including fetal growth restriction, preterm labour, cerebral palsy and septicaemia, although the underlying mechanisms are poorly understood.(3)

CASE REPORT: 24 yrs old lady was seen in emergency department with chief complaints of acute abdomen with 14 weeks pregnancy. Patient had a history of fever since two days. After ruling out preterm labor patient was sent for ultrasonography. It revealed bilateral pyelonephritis more on right side and no calculi was seen. She was hospitalized and further investigated. She was diagnosed to have moderate anemia with severe urinary tract infection with abundant pus cells. She was married since 1 year and had honeymoon cystitis for which she took treatment from a local practitioner. Then repeatedly she developed urinary tract infection on and off and was never relieved of symptoms. She was on long intravenous antibiotic therapy. Meanwhile she conceived and had this episode of acute abdomen at 14 weeks of pregnancy. She was kept on symptomatic treatment as organisms were resistant to all kind of antibiotics which are s safe in pregnancy. The decision of DJ stenting was taken, She was kept under antibiotic coverage. At 16 weeks USG guided rt. Sided DJ stenting was done.

Whole pus was drained and she was relieved of pain. She was kept under close observation and USG was performed to know the position of stent after 1 week.

Then her antenatal period was uneventful without but at around 36 weeks again she developed urinary tract infection which was treated. She underwent an elective LSCS for Cephalopelvic disproportion. Stent was removed at $6^{\text {th }}$ week post-partum and now patient is comfortable with healthy baby.

DISCUSSION: Pyelonephritis was found in $0.7 \%$ of deliveries. The mean maternal age was $24 \pm 5.83$ years with 51\% primiparity. Most (58.8\%) occurred in the second trimester. The main symptoms were loin pain (96.2\%) and abdominal pain (84.6\%). It was more common on the right side in $67 \%$ of cases. On urinalysis, $81.4 \%$ had pyuria. 
The commonest organism was Escherichia coli, in $61 \%$ of cases. ${ }^{(1)}$ Complications included $32 \%$ threatened preterm labour and $17 \%$ preterm delivery. About $6 \%$ of neonates had intrauterine growth restriction. There were no ICU admissions and no deaths. Conclusion. Early recognition and treatment of pyelonephritis result in good outcome. The condition is more prevalent in patients with the sickle cell gene and recurrence is high.

The establishment of urinary tract infection (UTI) outside pregnancy requires the adherence of E. coli to epithelial receptors, which facilitate the ascending colonisation of the urogenital tract.(4) To date, UTI in pregnancy is explained by obstruction of urine outflow by the gravid uterus, with little attention paid to the pregnancy-related alterations in the immune system, and the receptoradherence etiology of the ascending UTI. Our prior analysis of E. coli virulence factors in gestational pyelonephritis showed a predominance of E. coli bearing Dr. adhesins (Dr+E. coli): $27 \%$ of UTI in the first, $26 \%$ in the second and $39 \%$ in the third trimesters. ${ }^{5}$

We propose that $\mathrm{Dr}^{+} \mathrm{E}$. coli can invade the renal interstitium, escape killing by leukocytes and persist within epithelial cells. Using an experimental rat model, $\mathrm{Dr}+\mathrm{E}$. coli was not only lethal during pregnancy, but resulted in chronic interstitial nephritis. ${ }^{6}$ We refer to the increased attraction of $\mathrm{Dr}+$ E. coli to maternal/fetal tissues as gestational tropism. For an asymptomatic patient, bacteriuria is defined as having two consecutive voided urine specimens with isolation of the same bacterial strain in quantitative counts of $\geq 10^{5} \mathrm{cfu} / \mathrm{ml}$. In clinical practice, however, only one voided urine specimen is typically obtained, and treatment is usually started in women with $\geq 10^{5} \mathrm{cfu} / \mathrm{ml}$ without obtaining a confirmatory repeat culture. As antibiotic resistance may be significant in urinary isolates, antimicrobial susceptibility testing should be performed and an appropriate antibiotic selected accordingly. The likely precipitating factors of urosepsis in this patient, include, but are not limited to: delayed antibiotic therapy, E. coli resistance to ampicillin, the lethality of invasive $\mathrm{Dr}^{+} \mathrm{E}$. coli, preexisting subclinical/chronic interstitial nephritis/pyelitis, immunosuppression/steroid use in the context of an underlying pyelonephritis, and the lack of access to the history of UTI and treatment.

The possible mechanisms resulting in the unexpected death may involve both microbial and host characteristics. Gestational age-dependent infection of pregnant women by $\mathrm{Dr}^{+} \mathrm{E}$. coli could be explained by a temporary increase in the expression of tissue receptor decay accelerating factor (DAF) , also called CD55, which is upregulated by progesterone. (6) An increased density of DAF receptors in the colon and urinary tract may allow for increased colonization by $\mathrm{Dr}^{+} \mathrm{E}$. coli, thereby temporarily increasing the risk for UTI. ${ }^{3}$ The biological complexity and molecular epidemiology of pyelonephritis suggest that obstruction is not the only factor leading to the risk of developing gestational UTI. Urine stasis and obstruction may favour infection in the presence of non-virulent random Gram-negative and Gram-positive species. Respectively, urosepsis in pregnant women may be associated with a less virulent random species, but this is inconsistent with the findings in the current case.

CONCLUSION: UTI which is ignored or not properly treated may get worsened upto pyelonephritis which is difficult to treat in pregnancy.

Maternal morbidity and obstetric outcomes do not differ between first- and second-/thirdtrimester pyelonephritis. First-trimester pyelonephritis should be aggressively treated to prevent adverse outcomes.

Early recognition and treatment of pyelonephritis result in good outcome. The condition is more prevalent in patients with the sickle cell gene and recurrence is high. 


\section{REFERENCES:}

1. J. C. Dawkins, ${ }^{1}$ H. M. Fletcher,${ }^{1}$ C. A. Rattray, ${ }^{1}$ M. Reid,${ }^{2}$ and G. Gordon-Strachan :'Acute: Pyelonephritis in Pregnancy A Retrospective Descriptive Hospital Based-Study' ISRN Obstetrics and Gynecology Volume 2012 (2012), Article ID 519321, 6 pages doi: 10.5402/2012/519321.

2. Karen L. Archabald, MD, MS, Alexander Friedman, MDChristina A. Raker, ScD , MD, MSc : Impact of trimester on morbidity of acute pyelonephritis in pregnancy: Jan. 26-31, 2009 American Journal of Obstetrics \& Gynecology Volume 201, Issue 4, Pages 406.e1-406.e4, October 2009.

3. Dovlatian AA, Morozov DV, The surgical treatment of suppurative destructive forms of acute pyelonephritis in pregnant women, Urol nefrol (mosk) 1996 Nov-Dec: 6: 19-23.

4. W. Anstruther Milligan M.B. (Aberd.), F. R. C. S. (Edin.): A Case of Pyelonephritis of Pregnancy: 25 AUG 2005 DOI: 10.1111/j.1471-0528.1906.tb08989.x.

5. Nowicki B.: Urinary tract infection in pregnant women: old dogmas and current concepts: Curr Infect Dis Rep2002; 4: 529-35.

6. Hart A, Nowicki BJ, Reisner B, Pawelczyk E, Goluszko P, Urvil P, et al. :Ampicillin-resistant Escherichia coli in gestational pyelonephritis: increased occurrence and association with the colonization factor Dr adhesin. J: Infect Dis2001; 183: 1526-9.

\section{AUTHORS:}

1. Preeti Amit Kale

PARTICULARS OF CONTRIBUTORS:

1. Associate Professor, Department of Obstetrics \& Gynaecology, BJMC \& Sasoon General Hospital, Pune.

FINANCIAL OR OTHER COMPETING INTERESTS: None

\section{NAME ADDRESS EMAIL ID OF THE} CORRESPONDING AUTHOR:

Dr. Preeti Amit Kale, Department of Obstetrics \& Gynaecology, BJMC \& Sasoon General Hospital, Pune. E-mail:drpreetikale@rediffmail.com

Date of Submission: 29/05/2015. Date of Peer Review: 30/05/2015. Date of Acceptance: 19/06/2015. Date of Publishing: 25/06/2015. 